\title{
Avaliação do índice de contaminação fúngica em doces de leite pastosos comercializados na região sudeste do Brasil
}

\section{Evaluation of the fungal contamination index in pasty milk sweets sold in southeastern Brazil}

\section{DOI: $10.46919 / \operatorname{archv} 1 n 6-010$}

Recebimento dos originais: 01/09/2020

Aceitação para publicação: 30/10/2020

\section{Adriana Novaes Rodrigues}

Doutora em Ciência pela Universidade de São Paulo /Faculdade de Medicina /Área de Patologia Instituição: Universidade de São Paulo - USP

Endereço: Av. Dr. Arnaldo, 455 - Cerqueira César CEP: 01246903 São Paulo - SP - Brasil E-mail: E-mail: a.novaes@live.com

\section{João Ozório Rodrigues Neto}

Doutor em Ciências pela UNIRIO -/Saúde Coletiva

Instituição: Fundação Oswaldo Aranha - FOA

Endereço: Campus Três Poços - Av. Paulo Erlei A. Abrantes, 1325 - Três Poços

Prédio 1 - Volta Redonda - RJ - CEP: 27240-560

\section{Cristiane Silveira Cunha}

Doutora em Ciências pela UNIRIO -/História da Medicina

Instituição: Fundação Oswaldo Aranha - FOA

Endereço: Campus Três Poços - Av. Paulo Erlei A. Abrantes, 1325 - Três Poços

Prédio 1 - Volta Redonda - RJ - CEP: 27240-560

\section{Bruno Sarcinelli}

Especialista em Cirurgia Geral

Instituição: Fundação Oswaldo Aranha - FOA

Endereço: Campus Três Poços - Av. Paulo Erlei A. Abrantes, 1325 - Três Poços

Prédio 1 - Volta Redonda - RJ - CEP: 27240-560

E-mail: sarcinellib@hotmail.com

\section{Cristiane Gorgati Guidorene}

Doutora em Neurociência e Neurologia pela Universidade Federal de São Paulo Instituição: Fundação Oswaldo Aranha - FOA

Endereço: Campus Três Poços - Av. Paulo Erlei A. Abrantes, 1325 - Três Poços

Prédio 1 - Volta Redonda - RJ - CEP: 27240-560

E-mail: crisgorgati@yahoo.com.br

\section{RESUMO}

Introdução: A contaminação alimentar pode comprometer a saúde humana, através das micotoxinas. O doce de leite é um alimento perecível, com validade limitada, principalmente, os de origem caseira, onde a falta de uma maior fiscalização, pode gerar aumento da contaminação fúngica. Objetivos: Avaliar o perfil de contaminação por fungos filamentosos nos doces de leite de origem caseira e industrial. Metodologia: Foram analisadas 60 amostras de doces de leite, sendo 30 de origem caseira e 30 
industrializados. A metodologia, utilizada para análise, foi à estabelecida pela Instrução Normativa $\mathrm{n}^{\circ} 62$, de 26.08.2003 do Ministério de Agricultura, Pecuária e Abastecimento do Brasil. Resultados: Dos 60 doces analisados,35\% estava contaminado. não foi encontrada uma diferença estatística significativa entre dos doces caseiros e industrializados, porém, doces industrializados apresentaram maior quantidade de colônias (média de 59,5 \pm 26,94 colônias/doce) que nos doces caseiros (média de 30,0 \pm 14,89 colônias/doce, MannWhitney $\mathrm{p}<0,01)$. Conclusões: Os produtos finais oferecidos aos consumidores de doce de leite encontram-se, em número expressivo, contaminados por fungos filamentosos de potencial patogênico.

Palavras-chave: Fungos, Armazenamento, Contaminação, Contaminação fúngica, Segurança alimentar.

\begin{abstract}
Introduction: Food contamination can compromise human health through mycotoxins. Dulce de leche is a perishable food, with limited validity, especially those of homemade origin, where the lack of greater supervision can lead to increased fungal contamination. Objectives: To evaluate the contamination profile by filamentous fungi in homemade and industrial milk sweets. Methodology: 60 samples of milk sweets were analyzed, 30 of which were homemade and 30 industrialized. The methodology, used for analysis, was the one established by Normative Instruction 62, of August 26, 2003 from the Ministry of Agriculture, Livestock and Supply of Brazil. Results: Of the 60 sweets analyzed, 35\% were contaminated. No statistically significant difference was found between homemade and industrialized sweets, however, industrialized sweets had a higher number of colonies (average of $59.5 \pm 26.94$ colonies / sweet) than in homemade sweets (average of $30.0 \pm 14,89$ colonies / sweet, MannWhitney p <0.01). Conclusions: The final products offered to consumers of dulce de leche are, in significant numbers, contaminated by filamentous fungi of pathogenic potential
\end{abstract}

Keywords: Fungi, Storage, Contamination, Fungal contamination, Food safety.

\title{
1 INTRODUÇÃO
}

A contaminação alimentar por agentes biológicos, químicos ou físicos, pode comprometer a saúde humana. As mudanças ocorridas no último século predispõem o homem a alimentar-se de maneira incorreta, tanto em quantidade, como em qualidade. Muitas vezes esta alimentação está relacionada a alimentos industrializados. Diariamente, ocorrem casos de doença com origem nos alimentos, que são responsáveis por elevados níveis de morbidade e mortalidade, particularmente para grupos de risco, como: as crianças, os idosos e os imunodeficientes. A incidência real das doenças transmitidas pelos alimentos não é conhecida (PEDROSO, 2009). O doce de leite é um alimento perecível, com validade limitada, principalmente os de origem caseira, onde a falta de uma maior fiscalização, pode gerar aumento da contaminação fúngica. Os gêneros Aspergillus, Penicilium, Fusarium são os mais descritos como contaminantes devido às micotoxinas, que possuem atividade carcinogênica, teratogênica e mutagênica, sendo muito relatadas na literatura científica (BLACK, 2006; LARONE, 2002). Com o aumento populacional, um estudo sobre a qualidade dos alimentos é de fundamental importância para o monitoramento do produto a ser consumido, principalmente porque, de acordo com o IBGE, o consumo de doce de leite no Brasil, chega a 350 gramas/habitante/ano (IBGE, 2009). 


\section{OBJETIVOS}

Avaliar o perfil de contaminação por fungos filamentosos nos doces de leite de origem caseira e industrial comercializados na região do Triangulo Mineiro, MG e Vale do Paraíba, no RJ, a fim de se conhecer seu potencial risco a saúde humana.

\section{METODOLOGIA}

Foram analisadas 60 amostras de doces de leite, sendo 30 de origem caseira adquiridas diretamente dos produtores localizados no Triangulo Mineiro e Interior do Estado do Rio de Janeiro e 30 industrializados, em dois lotes diferentes, provenientes de 10 marcas comercializadas nas mesmas regiões, com data de validade para 2015. As amostras foram adquiridas entre os meses de dezembro 2013 e março de 2014. As amostras foram destinadas ao laboratório na embalagem original e estocadas a temperatura ambiente, protegida da umidade, não havendo violação da embalagem antes do início do experimento-(SILVA e SILVEIRA, 2001). A metodologia utilizada para análise foi à estabelecida pela Instrução Normativa $n^{\circ}$ 62, de 26.08.2003 do Ministério de Agricultura, Pecuária e Abastecimento (BRASIL, 2001).

\section{RESULTADOS}

Ao todo encontramos 21 doces contaminados dentre os 60 analisados (35\%). Quando analisamos os doces caseiros e industrializados separadamente não foi encontrada uma diferença estatística significativa uma vez que 36,66\% dos doces caseiros e 33, 33\% dos industrializados apresentaram contaminação. Porém, ao analisarmos apenas os 11 doces caseiros e 10 doces industrializados que estavam contaminados, vimos que a quantidade de colônias encontradas nestes foi significativamente maior nos doces industrializados (média de 59,5 \pm 26,94 colônias/doce) que nos doces caseiros (média de 30,0 $\pm 14,89$ colônias/doce, MannWhitney p<0,01).

\section{CONCLUSÕES}

Os produtos finais oferecidos aos consumidores de doce de leite encontram-se, em número expressivo, contaminados por fungos filamentosos de potencial patogênico, sendo necessária a implementação conjunta de várias ações como a fiscalização mais aprimorada pelos órgãos públicos, a promoção de educação em higiene de alimentos para os manipuladores e proprietários, minimizando os riscos ao consumidor e à saúde humana. 


\section{REFERÊNCIAS}

BLACK, M.H.; HALMER, P.. In: Michael H.. The encyclopedia of seeds: science, technology and uses. Wallingford, UK: CABI, 2006. 226 p. ISBN 978-0-85199-723-0.

BRASIL. Ministério da Saúde. Agência Nacional de Vigilância Sanitária. Resolução RDC nº 12, de 02 de janeiro de 2001. Aprova o Regulamento Técnico sobre os padrões microbiológicos para alimentos. Diário Oficial da União, Brasília, DF, 02 jan. 2001

IBGE. Anuário Estatítico do Brasil. 2008-2009.

LARONE, D.H. Medically Important Fungi: a guide to identification .4 ed. Washington: ASM Press; 2002.

PEDROSO, L.. Segurança Alimentar e Saúde Pública / Food Safety And Public Health. Revista Lusófona de Ciências e Tecnologias da Saúde, América do Norte, Jul. 2009. SILVA, N.; JUNQUEIRA; V.C.A; SILVEIRA, N.F.A. Manual de métodos de análise Microbiológica de alimentos. 2 ed. São Paulo: Varela; 2001 